\title{
On the validation of the LS-DYNA Geo Metro numerical model
}

\author{
Dawid Bruski ${ }^{1}$, Stanisław Burzyński ${ }^{1}$, Jacek Chróścielewski ${ }^{1}$, Lukasz Pachocki ${ }^{1 *}$ and Wojciech Witkowski ${ }^{1}$ \\ ${ }^{1}$ Gdańsk University of Technology, Faculty of Civil and Environmental Engineering, Department of Mechanics of Materials and \\ Structures, ul. Narutowicza 11/12, 80-233 Gdańsk, Poland
}

\begin{abstract}
The paper presents experiences gained during work with numerical model of Geo Metro vehicle used for simulations of crash tests with road safety barriers. Attention is drawn to the subject of tire/wheel breakage during collision events. Some methods for improvement of the model are presented in the paper. Several results for the normative vehicle numerical tests are introduced. Simulations were carried out using LS-DYNA finite element code with solver version R8.1.
\end{abstract}

\section{Introduction}

Finite element modelling plays important role in civil engineering and automotive industry. Specifically, intensive work is being done towards safety of passengers during collisions. In Europe numerical simulations in this area are subjected to the normative documents [1-2]. For example [2] contains guidelines for the development of road safety barriers and vehicle's numerical models. Annex C covers the list of tests that should be performed to validate the numerical model of vehicle, which should check an overall behaviour of its motion capabilities. Therefore, when numerical vehicle passes those tests it may be considered as a reliable tool in crash test simulations. In this paper LS-DYNA finite element code $[3,4]$ version R8.1 has been used for crash test modelling and numerical analysis.

The smallest car used in normative crash-test [1] is $900 \mathrm{~kg}$ passenger car. Due to its low weight and small dimensions, its passengers are exposed to relatively high injury risk, caused by large accelerations that occur during collision. The crucial parameter ASI [1] is calculated from accelerations at a basis of car's centre of weight. The Geo Metro (also known as Suzuki Swift) car meets all normative requirements and can be used in certifying process for road barriers on the basis of numerical simulations.

In the past Geo Metro's LS-DYNA model was available on public NCAC database [5], nowadays it can be downloaded from ROBUST Project repository [6]. Description of the improvements made to the model is also included and is greatly acknowledged [7]. During the numerical simulations of the road safety systems the proper behaviour of the vehicle plays crucial role. Many articles on the subject of numerical simulations have already been published e.g. [8-16]. Those papers contained the results of analyses with wide range of different vehicles.
It could be observed that in many experimental crash tests the elements of a vehicle that first contact the barrier for a longer time are wheels. Therefore, mechanical behaviour of wheels and their parameters in numerical model (e.g. stiffness of material, air pressure inside tires, capability of tire blowout, etc.) are crucial for proper simulation of full-scale experimental tests.

The vehicles used in [8-16] contained a simplified wheel model that proved to be sufficient for the most cases. More detailed wheel modelling approach has been used in papers [17-23]. As observed in a large number of full-scale crash tests many cars end up with broken suspension as well as damaged tire or wheel. Some examples of damaged cars are presented in Fig. 1. Different car types can be also subjected to this type of damage as shown in Fig. 2. This problem arises when, for example, there is a curb or other type of geometrical irregularity on a barrier and a vehicle contacts it first. Also, many accidents may be caused by the tire's adhesion loss. This indicates that there is a need to predict such events during numerical simulation as well. On the other hand, applicable balance between the computation time and the level of detail of the model must be preserved. The reason for this is that the numerical model must still be suitable for use during crash test simulation against e.g. $60 \mathrm{~m}$ long road safety systems. Due to the large number of numerical simulations that have to be performed during the conducted by the authors research project RID 3A "Road Safety Equipment", some improvements in the Geo Metro numerical model had to be introduced to fulfil the requirements of the standards $[1,2]$ and at the same time to provide a reasonable calculation time.

The paper is organized as follows. Section 2 gives brief description of the first version of the acquired numerical model. Section 3 shows the changes implemented into current version of the car model. General overview of the required validation tests with the

* Corresponding author: lukasz.pachocki@pg.edu.pl 
corresponding results is included in section 4 . In the last section general conclusions are presented.
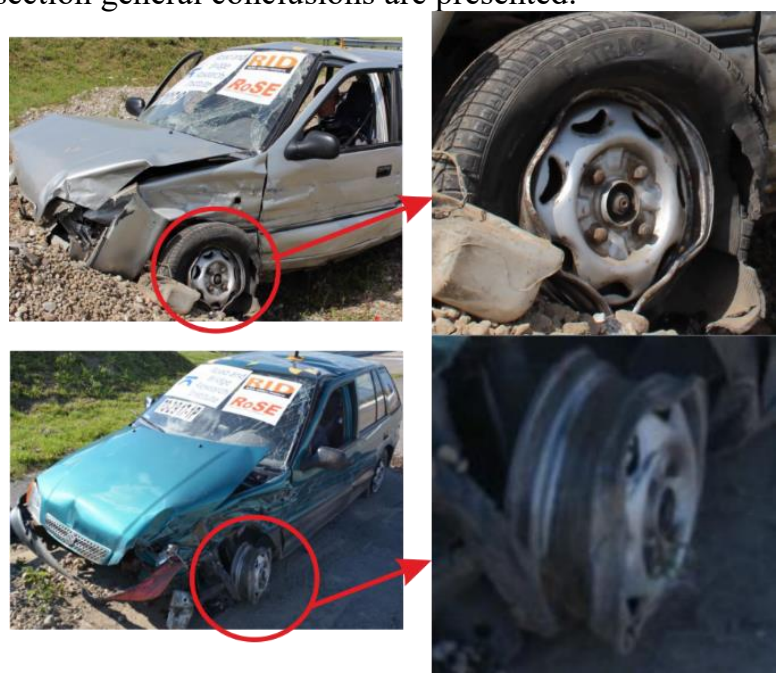

Fig. 1 Broken wheels/tires

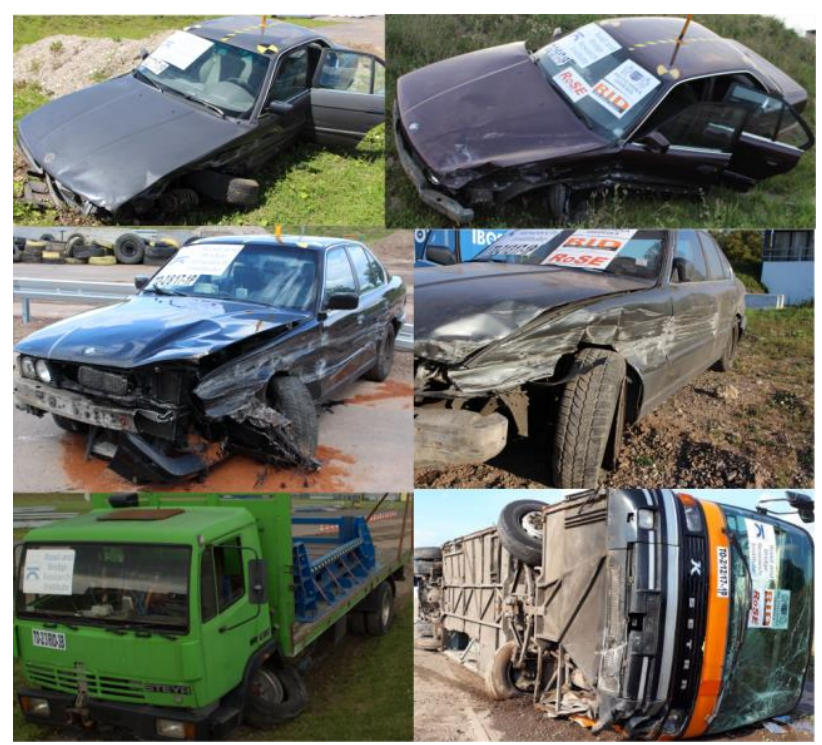

Fig. 2 Broken wheels or tires

\section{Description of the Geo Metro numerical model}

Numerical model of Geo Metro was downloaded from the NCAC public repository [5]. Other versions of this vehicle, available on the website [6], were also used. According to [7] this car was validated and can be used for a numerical simulations of the crash events. It was successfully used in wide range of simulations [7, 14, 21]. The main advantage of the model is its relatively small number of finite elements resulting in short required computational time.

The general view of the vehicle is presented in the Fig. 3. It consists of 14709 shell elements and 820 solids which corresponds to 19279 nodes. Most of the parts of the vehicle are modelled with piecewise linear plasticity with element failure material. Discrete dampers along with springs were used to model shock absorbers. Springs had the constant stiffness value equal to $k=344.0 \frac{\mathrm{N}}{\mathrm{mm}}$. Corresponding discrete elements had initial offset set to (negative values mean compression):

- front suspension $->$ offset $=-7.3 \mathrm{~mm}$,

- $\quad$ rear suspension $->$ offset $=-3.6 \mathrm{~mm}$.

Viscous damper with coefficient equal $d c=8.93 \frac{\mathrm{N} \cdot \mathrm{s}}{\mathrm{mm}}$ was used. Tires are modelled using LS-DYNA airbag logic *AIRBAG_SIMPLE_AIRBAG_MODEL. Ambient pressure of the gas was set to $p_{e}=0.1 \mathrm{MPa}$ and other gas constants were specified as for the air. Input mass flow rate was calculated so the pressure inside the tires could reach the value of $p=0.2 \mathrm{MPa}$. Actual Geo Metro vehicle suspensions are McPherson type and were recreated using various types of joints along with rigid bodies. Detailed description can be found in literature [7]. Standard initial conditions of the vehicle are set using translational velocity of all parts and angular velocities about corresponding wheel's rotational axis.

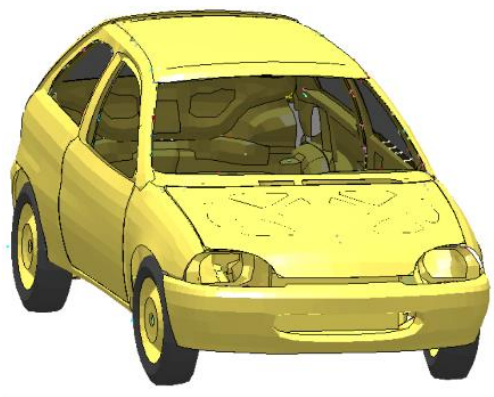

Fig. 3 General view of the Geo Metro's numerical model

\section{Description of the changes done to the model}

The numerical model has been subjected to several changes. First of all, mesh refinement was required in areas that potentially will contact with the barrier. General comparison of the discretization is given in Fig. 4 . Originally, vehicle's radiator was made of solid elements with honeycomb material law, what sometimes led to numerical instabilities. Thus, it was substituted with shell elements with steel elastic material law. A lot of attention was devoted to recreate proper wheel geometry and mesh. Alternative way of initial pressure adaptation was introduced that lead to further model improvements. Suspensions were also analysed and checked for the correctness of the system behaviour.

The improvements were divided into three separate categories. The first of them concerns general improvements and have already been described. Section 3.1 contains brief description of changes done to the vehicle's wheels. Last category is presented in section 3.2 and contains the changes performed on suspension. 


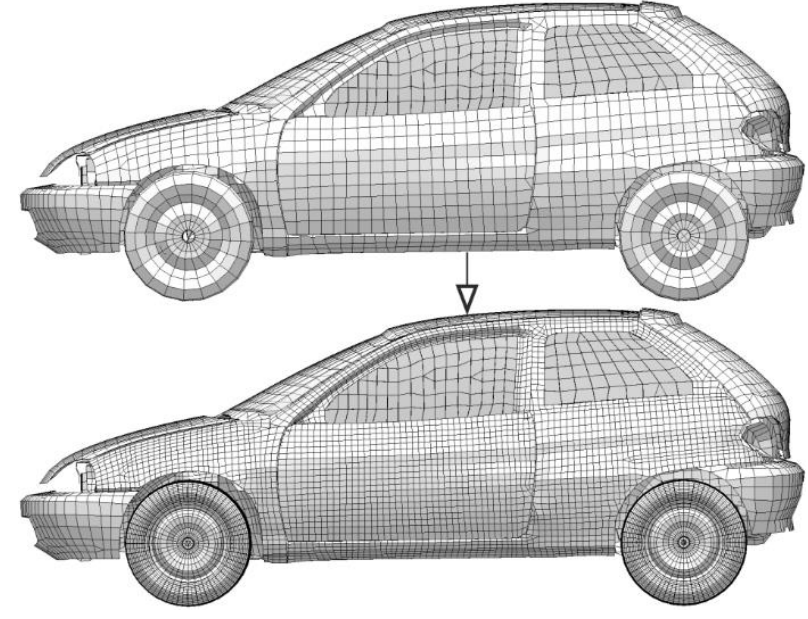

Fig. 4 Geo Metro numerical model mesh refinement

\subsection{Description of the wheels modifications}

Tires are the only parts of the vehicle that remain in constant contact with the roadside. They are designed to absorb minor road unevenness as well as to transfer loads when encountering obstacles like curbs or geometrical irregularities. They may undergo large deformations so the finite element mesh should be dense. Fig. 5 (left side) shows the initial mesh of the wheel's numerical model of the Geo Metro. It is composed of a tire and a rim which are merged together. New, refined model of the wheel (Fig. 5, right side) consists of several parts:

- rim,

- tire,

- virtual tire air boundary,

- tire reinforcement (steel fibres),

- bead coils.

Tire and rim geometry and applied materials were based on the NHTSA's Toyota Yaris numerical model [24]. Then the tire bead and the virtual boundary of the air on the rim were created. The behaviours of the tire components were assumed as elastic. The steel fibres were modelled using truss beam elements placed on the edges of the shell elements. The separation between parts enabled the use of more coarse mesh in the rim so the critical time step could be preserved. Furthermore this approach provides better accuracy of modelling the actual wheel-tire configuration. Fig. 6 depicts the cross-section of the wheel's numerical model. It contains descriptions for simplified wheel components with their placement.

Another modification introduced to the model was the change in the AIRBAG keyword. Initially, the pressure was introduced due to ambient pressure equal to $p_{e}=0.1 M P a$ along with input mass flow of the air resulting in final pressure equal $p=0.2 \mathrm{MPa}$. The idea was to simplify this approach and enable the usage of the mass flow feature in future simulations. Therefore, the whole simulation runs under vacuum conditions. It was assumed that inside the closed volume of the tire there is ambient pressure equal to $p_{e}=0.2 \mathrm{MPa}$. Therefore no additional input mass flow of the air is needed. LS-DYNA airbag logic $[3,4]$ allows the user to establish conditions for the so-called sensors that can cause an inflation/deflation of an airbag. These sensors $[3,4]$ were modelled as the rigid parts marked red in Fig. 6.
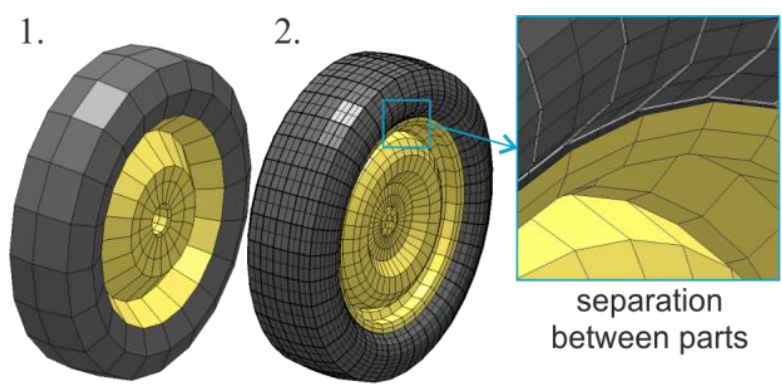

Fig. 5 Different approaches for wheel modelling

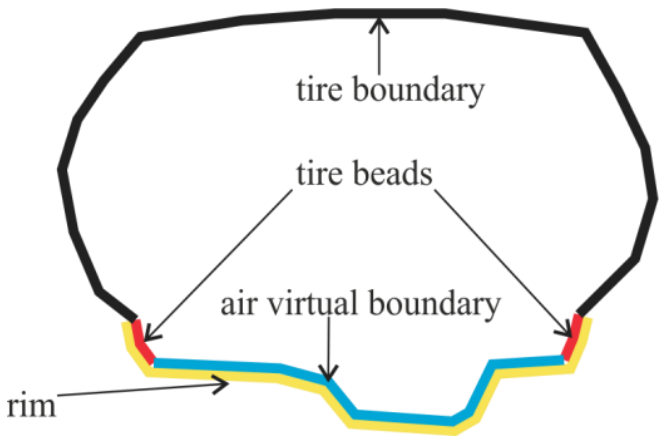

Fig. 6 Cross-section of wheel's numerical model

\subsection{Description of the suspension modifications}

Suspension of a vehicle is the second level (besides wheels) of load transfer system. It maintains vehicle parts connected to the driving system. Therefore, it is crucial to use its appropriate parameters. It was decided to apply actual wheel tracks. During full-scale crash test appropriate values have been measured and then adapted to the numerical model. The front and rear wheel track are equal to $1.375 \mathrm{~m}$ and $1.345 \mathrm{~m}$ respectively. Wheel's convergence was set according to Geo Metro numerical model [6] and online tutorial [25]. Positive 'toe-in' alignment was applied with toe angle equal to $3^{\circ}$. Camber angle was set to $2^{\circ}$. Further changes were concerned with the spring and damper discrete elements. The value of stiffness was acquired from the actual Geo Metro spring found in online shop. The following equation (1) was used for the discrete spring stiffness calculation:

$$
k=\frac{d_{\text {wire }}{ }^{4} G}{8\left(D_{\text {coil }}-d_{\text {wire }}\right)^{3} N_{\text {active }}}
$$

where $G$ was used to describe the stiffness modulus of the spring material, $D_{\text {coil }}$ means the diameter of the coil and $d_{\text {wire }}$ is the diameter of the single wire. The last parameter $N_{\text {active }}$ describes the number of the coils that remain active. From equation (1), the front stiffness value was calculated as $k_{\text {front }}=25.14 \mathrm{~N} / \mathrm{mm}$ and for the rear was found to be equal to $k_{\text {rear }}=66.95 \mathrm{~N} / \mathrm{mm}$. The damping coefficients were calculated assuming critical damping ratio. This led to the determination of the damping coefficient for the front damper $d c_{\text {front }}=5.48 \mathrm{~N} \cdot \mathrm{s} / \mathrm{mm}$ and the rear damper 
$d c_{\text {rear }}=8.94 \mathrm{~N} \cdot \mathrm{s} / \mathrm{mm}$. The last stage of model modifications aimed at establishing the proper initial offset value. Initial force in springs was assumed proportional to the one fourth of the vehicle weight. Therefore calculated values were equal to offset $_{\text {front }}=-116.44 \mathrm{~mm}$ for the front discrete spring elements and offset $_{\text {rear }}=-66.25 \mathrm{~mm}$ for the rear discrete spring elements.

\section{Results}

\subsection{Description of the tests}

In order to validate the vehicle's numerical model a series of tests shall be performed. According to [2] 24 different tests should be carried out. They are meant to check overall stability of the model as well as the proper behaviour of the suspension system. The tests can be grouped into several different categories:

- suspension loads,

- idle,

- linear track

- circular tracks,

- curb testing,

- rigid wall testing,

- full-scale crash against deformable barrier.

\subsection{Results of the tests}

Suspension loads tests were performed by fixing all degrees of freedom of chassis side members. Rigid shell below the tires was used to apply force equal to $F=4000 \mathrm{~N}$ in 8 variations according to [2]. Correct behaviour of the system was achieved. Idle test was carried out for the duration time of 3 seconds and the simulation remained stable. Linear track test was run with two different initial conditions. The initial velocities were compared with corresponding deviation from the original track after $30 \mathrm{~m}$ of free ride (Table 1). Referring to the circular tests, vehicle was able to maintain the circular motion and then moved along the appropriate tangent to that circle. Then, the series of curb tests were performed. Geometry of the $100 \mathrm{~mm}$ height obstacle was based on standard [2]. The initial velocity was set to $15 \mathrm{~km} / \mathrm{h}$. The course of the exemplary test for both front wheels and curb is presented in the Fig. 7. Then the tires along with the springs absorb the unevenness and vehicle crosses the obstacle with the front tires at the height of about $100 \mathrm{~mm}$. After that vehicle's front suspension absorbs the landing, returns and stops in the initial configuration due to the selection of the critical damping in the viscous dampers. Other curb tests also shown correct behaviour.

Table 1. Linear tests results

\begin{tabular}{|c|c|}
\hline $\begin{array}{c}\text { Initial velocity } \\
\mathrm{km} / \mathrm{h}\end{array}$ & $\begin{array}{c}\text { Deviation from original track } \\
\mathrm{mm}\end{array}$ \\
\hline 100 & 28 \\
\hline 140 & 26 \\
\hline
\end{tabular}
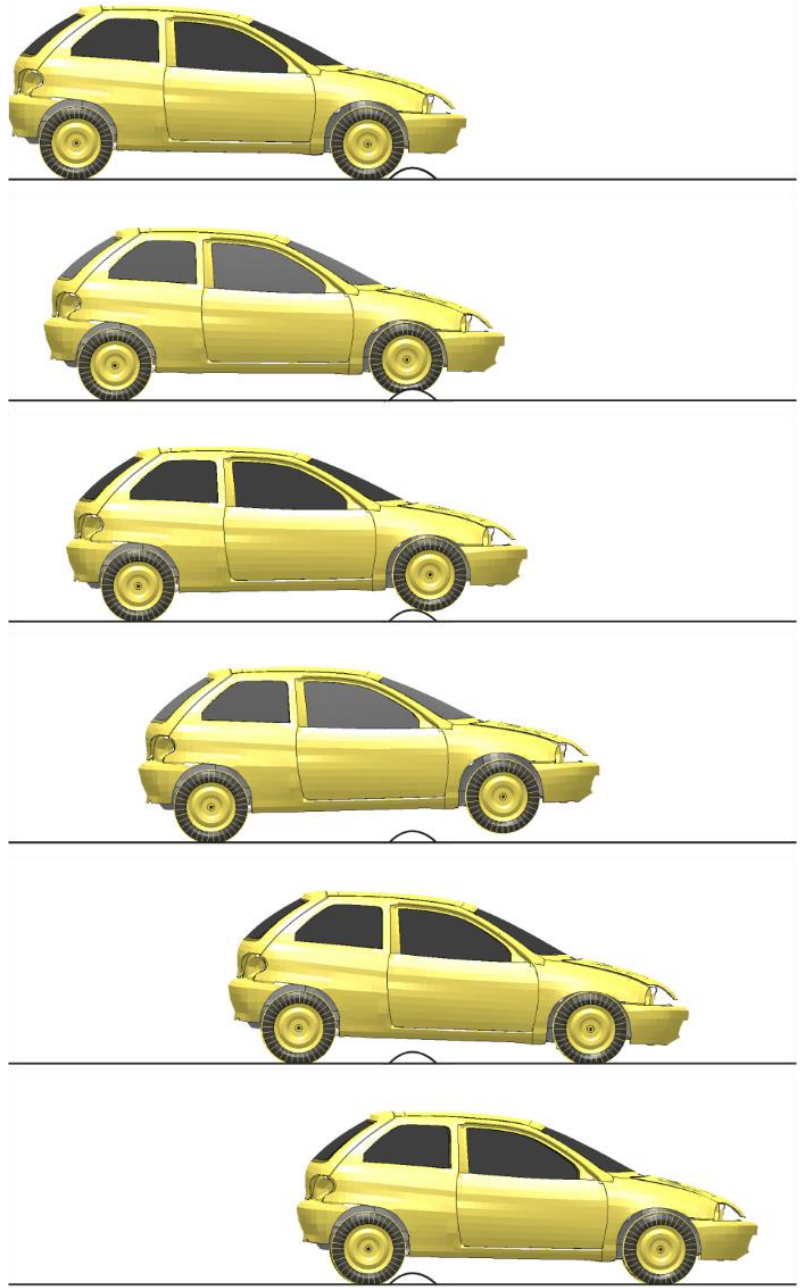

Fig. 7 The course of the front suspension curb test

Next type of tests were crash tests against rigid wall. There is no specification for the wall geometry so its height was assumed as $h=700 \mathrm{~mm}$. Keyword used for its description was *RIGIDWALL_PLANAR_FINITE. Three tests were conducted with the variable initial velocity, equal to $V_{\text {init }}=60 \mathrm{~km} / \mathrm{h}, V_{\text {init }}=100 \mathrm{~km} / \mathrm{h}$ and $V_{\text {init }}=140 \mathrm{~km} / \mathrm{h}$. The impact angle was assumed as $20^{\circ}$. In all three tests vehicle hit the wall and was properly redirected. The exemplary test for the initial velocity $60 \mathrm{~km} / \mathrm{h}$ is shown in Fig. 8. Frontal view of the vehicle at the last state is also included in Fig. 9. Two remaining tests revealed that the front left wheel/suspension of the vehicle collapsed. For the test with velocity equal to 100 $\mathrm{km} / \mathrm{h}$ similar behaviour was also observed in paper [7]. The resulting impact severity indexes are summarised in Table 2. The presented results show that with the increasing speed the ASI parameter is also increasing. Qualitative assessment of the rigid wall tests results leads to the conclusion that realistic behaviour of the Geo Metro numerical model is obtained. 


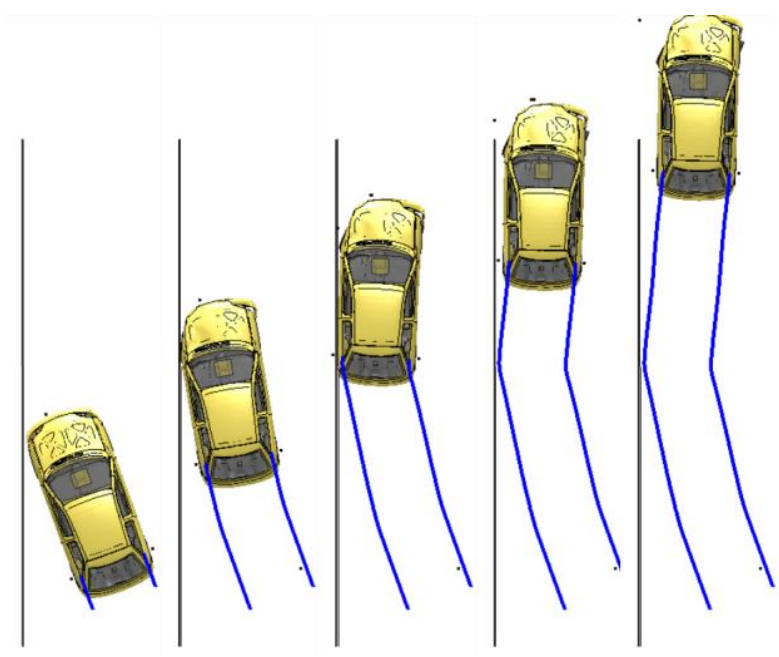

Fig. 8 The course of the Geo Metro $60 \mathrm{~km} / \mathrm{h}$ crash test against rigid wall

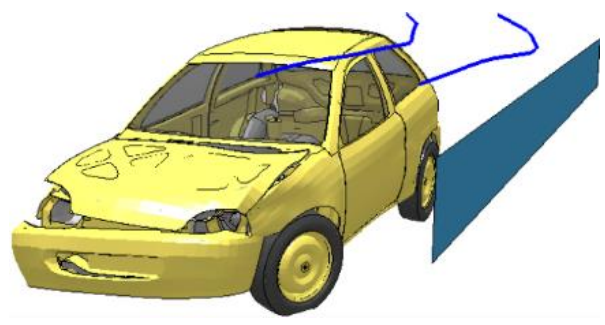

Fig. 9 Front view of the Geo Metro $60 \mathrm{~km} / \mathrm{h}$ crash test against rigid wall

Table 2. Results for the Geo Metro crash tests against rigid wall for different initial velocities

\begin{tabular}{|c|c|c|}
\hline $\begin{array}{c}\text { Initial Velocity } \\
\mathrm{km} / \mathrm{h}\end{array}$ & $\begin{array}{c}\text { ASI } \\
-\end{array}$ & $\begin{array}{c}\text { THIV } \\
\mathrm{km} / \mathrm{h}\end{array}$ \\
\hline 60 & 1.2 & 8.0 \\
\hline 100 & 2.2 & 7.7 \\
\hline 140 & 3.0 & 9.1 \\
\hline
\end{tabular}

The last test was carried out for two Geo Metro numerical models: the original and the improved one. They were performed in order to make a comparison between results from two models and to analyses the potential differences. The test was concerned with the TB11 collision against deformable road safety system. N2/W4/A steel road barrier was used due to the availability of the full-scale crash tests results. Fig. 10 shows general overview of the TB11 crash test course. The initial Geo Metro model is marked with yellow colour and the new one with green. It can be observed that vehicles impact into the barrier at the same point. However, yellow Geo Metro is redirected at the angle similar to the impact one. On the other hand, green vehicle moves away from the barrier almost parallel to it. Referring to the full-scale crash test results the second behaviour is correct. Close-up view of the differences in the behaviour can be seen in Fig. 11. Despite the changes introduced so far more improvements might be made as in full scale crash test it was observed that the vehicle's wheel was completely detached from its axis of rotation. Moreover, it is frequently observed that the contact of the wheel with the geometrical irregularities at high speed results in the tire blowout.

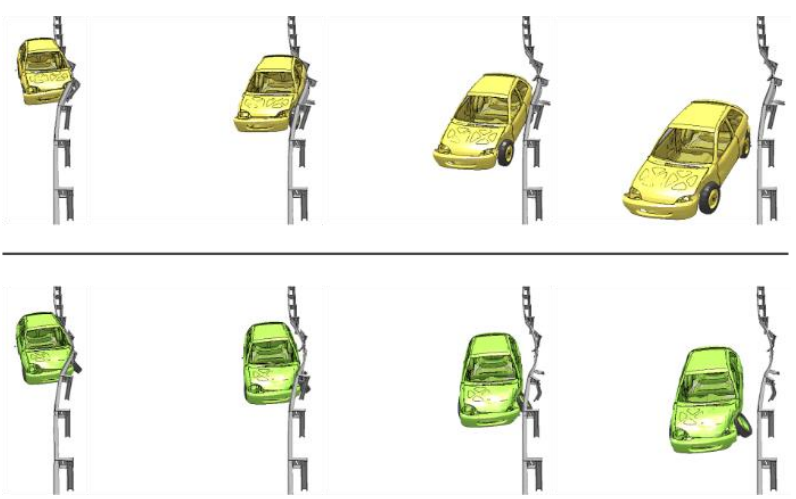

Fig. 10 Comparison between courses of the TB11 crash tests against N2/W4/A steel road safety barrier

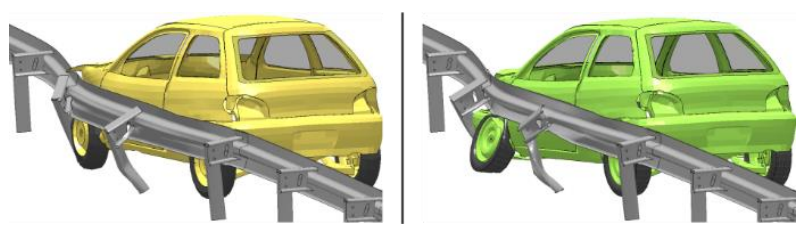

Fig. 11 Comparison between the Geo Metro's wheel behaviour

\section{Conclusions}

This paper presents general description of the modifications that were implemented to Geo Metro numerical model. The numerical results of several tests proved the improvement of the model and its ability in proper vehicle's behaviour. Some additional ideas for the future development of the model have been introduced.

\section{Acknowledgments}

This work was supported by the National Centre for Research and Development (NCBiR) and General Director for National Roads and Motorways (GDDKiA) under the research project "Road Safety Equipment" (contract number DZP/RID-I-67/13/NCBR/2016). Calculations were carried out at the Academic Computer Centre in Gdańsk, Gdańsk University of Technology, Poland.

\section{References}

[1] European Standard EN 1317-1-5, (2010)

[2] British Standard PD CEN/TR 16303-1-5, (2012)

[3] J.O. Halquist, LS-DYNA Theory Manual, USA, 2006

[4] Livermore Software Technology Corporation, LS-DYNA Keyword User's Manual, USA, (2015)

[5] National Crash Analysis Center, Crash Simulation Vehicle Models (accessed 10.03.2016)

[6] ROBUST PROJECT, https://www.vegvesen.no/s/robust/Computational _mechanics/Vehicle\%20models/

[7] ROBUST PROJECT, WP5-Computational Mechanics Geo-Metro Finite Element model 
(GM_R3): Improvements of Steering System and Suspensions, I, (2005)

[8] T. Teng, C. Liang, T. Tran, Simulation, 92(6), 565578, (2016)

[9] K. Jamroz, S. Burzyński, W. Witkowski, K. Wilde, Advences in Mechanics: Theoretical, Computational and Interdisciplinary Issues, p.231234, (2016)

[10] W. Borkowski, Z. Hryciów, P. Rybak, J. Wysocki, JKONESPaT, 17, 65-71, (2010)

[11] M. Brovinsek, M. Vesenjak, M. Ulbin, Z. Ren, EFA, 14, 1711-1718, (2007)

[12] K. Wilde, K. Jamroz, D. Bruski, S. Burzyński, J. Chróścielewski, W. Witkowski, JCEEA, XXXIII, 455-467, (2016)

[13] M. Klasztorny, D. Nycz, P. Szurgott, IJoC, 21:6, 644-659, (2016)

[14] K. Wilde, D. Bruski, S. Burzyński, J. Chróścielewski, W. Witkowski, DSTA, 555-566, (2017)

[15] M. Klasztorny, K. Zielonka, D. Nycz, P. Posuniak, R. Romanowski, ACME, 18, 339-355, (2018)

[16] K. Wilde, K. Jamroz, D. Bruski, M. Budzyński, S. Burzyński, J. Chróścielewski, W. Witkowski, ACME, 63, 187-199, (2017)

[17] P. Baranowski, J. Małachowski, J. Janiszewski, J. Weekezer, Materials and Design, 96, 68-79, (2016)

[18] P. Baranowski, J. Małachowski, L. Mazurkiewicz, IJoMS, 106, 346-356, (2016)

[19] P. Baranowski, J. Janiszewski, J. Małachowski, JoTaAM, 55, 727-739, (2017)

[20] P. Baranowski, J. Małachowski, Bulletin of the Polish Academy of Sciences, 63, 867-878, (2015)

[21] F. Orengo, M. H. Ray, C. A. Plaxico, ASME, (2003)

[22] J. D. Reid, D. A. Boesch, R. W. Bielenberg, ICrash, (2006)

[23] Y. Cai, M. Zang, Y. Chen, W. Liu, JoAE, 228(9), 1116-1124, (2014)

[24] National Highway Traffic Safety Administration, Crash Simulation Vehicle Models (accessed 26.02.18)

[25] http://what-when-how.com/automobile/frontwheels-alignment-automobile/ 